\title{
¿Seguridad jurídica en el sector minero? Una aproximación desde el principio de coordinación
}

Legal security in the mining sector? An approach from the principle of coordination

Autor: Cristian Alexis López Solano

DOl: https://doi.org/10.25058/1794600X.994

\footnotetext{
SP MISIÓN JURÍDICA A 


\section{¿SEGURIDAD JURÍDICA EN EL SECTOR MINERO? UNA APROXIMACIÓN DESDE EL PRINCIPIO DE COORDINACIÓN*}

\author{
LEGAL SECURITY IN THE MINING \\ SECTOR? AN APPROACH FROM THE \\ PRINCIPLE OF COORDINATION
}

SEGURANÇA JURÍDICA NO SETOR DE
MINERAÇÃO? UMA ABORDAGEM DESDE 0
INÍCIO DA COORDENAÇÃO

\section{Resumen}

El sector minero ${ }^{1}$ se encuentra en un momento coyuntural del que depende la estabilidad de la industria. De allí que resulte imperioso el estudio del fenómeno de inseguridad jurídica, pues este es uno de los retos que debe afrontar el sector.

La aplicación del principio de coordinación resulta útil para minimizar la tensión existente entre el principio de estado unitario y el de autonomía territorial; más aún cuando en Colombia existe un sistema público de actividad transversal, es decir, de actividad conjunta entre diferentes órganos estatales.

1. Cabe resaltar que no es exclusivamente el sector minero, también se encuentran incluidos el hidrocarburífero, el de gas y el de energía eléctrica.

* Artículo de reflexión que presenta un análisis crítico de los problemas que se originan debido a la falta de aplicación del principio de coordinación en el ejercicio de las diferentes competencias de los distintos órganos estatales. Existe un especial énfasis en la disputa que se origina por el choque de los principios de Estado Unitario y el de Autonomía Territorial.

a. Abogado egresado de la universidad Santo Tomás de Aquino, Especialista en Derecho de la Contratación Estatal de la Universidad Externado de Colombia, Magister en Derecho Público con Énfasis en Regulación Minera, Energética y Petrolera (c) de la Universidad Externado de Colombia.

Cristian Alexis López Solano ${ }^{a}$ cristian.lopez.solano@gmail.com

Fecha de recepción: septiembre 29 de 2018 Fecha de revisión: octubre 10 de 2018 Fecha de aceptación: noviembre 06 de 2018
Para citar este artículo:

López, C. (2019). ¿Seguridad jurídica en el sector minero? Una aproximación desde el principio de coordinación. Revista Misión Jurídica, 12, (16), 263 $-280$. 
La actual jurisprudencia de la Corte Constitucional abre la posibilidad de excluir la actividad minera de un municipio pues es una competencia constitucional que surge de una interpretación armónica de las disposiciones constitucionales. Pero esto no resuelve el problema, lo que se genera es un empoderamiento irracional que no observa otros postulados de gran valor como lo es la libertad de empresa y la garantía de los derechos adquiridos por un contrato. La solución no se encuentra en prohibir, sino en concertar, en realizar un acuerdo contractual entre los sectores privados y públicos que se ven involucrados, todo sobre la base del principio de coordinación ${ }^{2}$.

\section{PALABRAS CLAVE}

Sector minero; seguridad jurídica; coordinación; principio; sistema transversal; libertad de empresa.

\section{ABSTRACT}

The mining sector is going through a conjunctural moment that depends on the stability of the industry. Thence, it is imperative to analyse the legal insecurity phenomenon because is one of the challenges that this sector has to confront.

The implementation of the principle of coordination is useful to minimize the tension that exists between the principle of unitary state and the principle of territorial autonomy, furthermore when Colombia has a public system of cross-cutting activity, that is to say of a joint activity among different state bodies.

The current jurisprudence of the Constitutional Court opens the possibility of excluding the mining activity of a district because is a constitutional competence that arises of an harmonic interpretation of the constitutional dispositions. But this does not solve the problem, which creates an irrational empowerment that does not take into account other assumptions of great value such as the freedom of Enterprise and the guarantee of the

2. No sólo se debe hablar de una socialización de las actividades, sino de una verdadera concertación o acuerdo de voluntades. Este debe quedar plasmado en documento público y no puede, bajo ningún parámetro, desconocer las competencias que la ley ha conferido a cada órgano tanto centralizado como descentralizado del estado. rights acquired by a contract. The solution does not lie in forbidding but in establishing, in creating a contractual agreement between the private and public sectors that are involved, all these in the basis of the principle of coordination.

\section{KEY WORDS}

Mining sector, legal security, coordination, principle, cross-cutting system, freedom of enterprise

\section{RESUMO}

O setor de mineração está em um momento conjuntural do qual depende a estabilidade da indústria. Assim, o estudo do fenômeno da insegurança jurídica é imperativo, uma vez que esse é um dos desafios que o setor deve enfrentar.

A aplicação do princípio de coordenação é útil para minimizar a tensão entre o princípio do status unitário e o da autonomia territorial; mais ainda quando na Colômbia existe um sistema público de atividade transversal, isto é, de atividade conjunta entre diferentes órgãos do Estado.

A atual jurisprudência do Tribunal Constitucional abre a possibilidade de excluir a atividade de mineração de um município, pois, em seu conceito, é uma competência constitucional decorrente de uma interpretação harmônica das disposições constitucionais. Mas isso não resolve o problema, o que é gerado é um empoderamento irracional que não observa outros postulados de grande valor, como a liberdade de negócios e a garantia de direitos adquiridos por um contrato. A solução não é proibir, mas concordar, fazer um acordo contratual entre os setores público e privado envolvidos, todos baseados no princípio da coordenação.

\section{PALAVRAS-CHAVE}

Setor Mineiro; segurança jurídica; coordenação; princípio; sistema cruzado; liberdade de negócios

\section{INTRODUCCIÓN}

De la lectura que realizamos a la Ley 685 de 2001 podremos válidamente afirmar que muchos de sus preceptos operan armónicamente con los postulados de nuestro Estado Social de Derecho y la Constitución Política de 1.991. El 
problema nace cuando en virtud del ejercicio de sus competencias el orden central (Estado Unitario) choca con las competencias del orden descentralizado (Entidades territoriales).

La falta de coordinación ${ }^{3}$ entre los órganos del orden central y los descentralizados ha decantado en situaciones tan absurdas como la siguiente: a un proponente para contrato de concesión minera se le aprueba el contrato de concesión y se firma, para la fecha del contrato el área se encontraba libre de cualquier afectación, ${ }^{4}$ por ende, el empresario comienza a elaborar sus estudios y trabajos de la fase exploratoria. Luego, con una fuerte inversión, dicho titular minero inicia la etapa de construcción y montaje, en esta desarrollan los trabajos para la explotación correspondiente. Luego de unos meses y con una inversión realizada, los entes territoriales realizan una consulta popular por medio de la cual prohíben el desarrollo de actividades extractivas en su territorio. Las preguntas que debemos hacernos son las siguientes: ¿Acaso dichas actuaciones por parte de la administración pública violan los derechos económicos del concesionario minero? ¿Qué propicia la inseguridad jurídica para la inversión en el sector minero? ¿Cómo se dirime dicha controversia?

\section{DESARROLLO DEL TRABAJO}

\section{METODOLOGÍA}

La tensión existente entre los principios de estado unitario y el de autonomía territorial ha sido propiciado en parte por las nuevas posturas que ha adoptado la Corte Constitucional en su jurisprudencia, por ello, a la luz de las Sentencias C-123 de 2014 y la T-445 de 2016, entre otras, se hará un estudio de los principios precitados y su influencia en la estabilidad del sector minero del país.

Además de ello, dentro del marco de los derechos fundamentales, es obligatorio analizar la competencia que tienen los entes territoriales

3. No puede entenderse que dicha coordinación envuelva exclusivamente a los órganos estatales, muy por el contrario, dicho principio debe involucrar a la población o personas individuales que llegaren a verse afectadas por la toma de cualquier tipo de determinación, más aún, cuando dicha decisión pudiere legar a poner en riesgo sus bienes jurídicos tutelados.

4. Entiéndase afectación como declaratoria por parte del Ministerio de Ambiente. y la nación para salvaguardar los mismos. Se verá a partir de la teoría de la concertación y la aplicación del principio de coordinación, como estos derechos entran en una dinámica incluyente con los derechos económicos de los que son beneficiarias las industrias extractivas.

Por lo anterior, y en virtud de lograr un mejor entendimiento de la idea central del presente escrito, se propone al lector el siguiente orden: 1. Principios: Principios constitucionales. Principios legales. 2. Desarrollo jurisprudencial. 3. Conclusión y propuesta.

\section{PRINCIPIOS}

Piénsese en las bases estructurales de un edificio, eso son los principios; una construcción moral sobre la que descansa nuestro ordenamiento jurídico, social y económico; es menester adentrarnos en su profundo e importante valor, más aún cuando estos se comportan como las vértebras que dan estructura a nuestra Constitución Política (Constitución Política de Colombia, 1991).

Recordemos que la Constitución Política de Colombia tiene unos fines esenciales, y que para la consecución de los mismos consagró unos principios que dan un marco y oriente a las actuaciones por parte de las entidades estatales y de los servidores públicos. En primer lugar, el artículo $1^{\circ}$ constitucional señala: "Colombia es un Estado Social de Derecho ${ }^{5}$ organizado en

5. Con la concepción moderna (la del siglo XXI) del Estado Social de Derecho se han incorporado en materia de derechos fundamentales los derechos sociales, o de segundo orden. Al respecto es válido afirmar que la nueva concepción constitucional que en Colombia se ha impreso con la Constitución Política de 1991, involucra una serie de derechos colectivos sobre los cuales se ha venido reinventando nuestra república, al punto de que las obligaciones económicas contraídas con anterioridad se han visto afectadas por la protección de los derechos fundamentales. Con acierto señaló (CARNELUTTI, 2008, Pág. 45), que "no hay caso entre los institutos jurídicos otro que como el contrato ponga en evidencia un proceso que yo llamaría de fecundación moral de la economía. La economía puede ser parangonada a la tierra sobre la cual esparciera la ética su semilla; sobre esa tierra y de esa semilla nace, crece y se agiganta el derecho. Yno hay en el complejo ordenamiento jurídico una vegetación más lozana que la del contrato. Sin él, la economía sería un páramo desolado". Así pues, resulta natural ver las relaciones contractuales particulares afectadas por las clausulas normativas del Estado; por ello, en el evento en que se realice un nuevo cambio de paradigma normativo, dichas relaciones contractuales se verán afectas. Tal es el caso del sector minero en la actualidad, pues para la fecha no se concibe una explotación minera como la que se desarrolló con anterioridad a la expedición de la Constitución Política de 1991. Ahora, dicha actividad económica debe armonizar con 
forma de república unitaria, descentralizada, con autonomía en sus entidades territoriales ${ }^{6}$, democrática, participativa y pluralista, fundada en el respeto de la dignidad humana, en el trabajo y la solidaridad de las personas que la integran y en la prevalencia del interés general" (Subrayados fuera del texto), de aquí se infiere que dentro de la concepción de nuestro Estado moderno se encuentran inmersos varios elementos axiológicos que pretenden la "prevalencia del interés general", es decir, el interés de la colectividad.

En conjunción con lo anterior, en el artículo $2^{\circ}$ de la Constitución Política se señala que los fines esenciales del Estado son:

(...) servir a la comunidad, promover la prosperidad general y garantizar la efectividad de los principios, derechos y deberes consagrados en la Constitución ${ }^{7}$; facilitar la participación de todos en las decisiones que los afectan y en la vida económica, política, administrativa y cultural de la nación; defender la independencia nacional, mantener la integridad territorial y asegurar la convivencia pacífica y la vigencia de un orden justo (Constitución Política de Colombia, 1991) (Subrayado fuera del texto).

la protección de las garantías fundamentales. De allí, el nuevo reto: armonizar la industria minera (dimensión económica), con los intereses colectivos (dimensión moral), mediante la incorporación de regulaciones apropiadas y que armonicen con las dos anteriores (dimensión legal).

6. La autonomía de los pueblos, o autodeterminación resulta un elemento de gran importancia en la actual concepción del derecho; pues de acuerdo con la nueva jurisprudencia de la Corte Constitucional (Sentencias C-123 de 2014: T-445 de 2016; C-389 de 2016) las determinaciones administrativas que se realicen desde el orden central, no pueden desconocer la autonomía o poder de auto-organización de la que gozan los pueblos. Dicha concepción obedece a que la protección del medio ambiente es un asunto que compete a la comunidad; la lógica de dicho concepto es que "la protección de los recursos renovables asegura la supervivencia de las generaciones presentes y futuras, condiciona el ejercicio de ciertas facultades que se ven limitadas por los derechos de quienes aún no han nacido, conforme a la función ecológica de la propiedad y obliga a actuar de determinada manera, dado que la satisfacción de las necesidades actuales requieren de planificación económica y de responsabilidad". Así las cosas, dicha autonomía se ha ampliado, y de ahí nacen un sinfín de consecuencias jurídicas y además de ello, retos en materia regulatoria.

7. Al respecto cabe destacar que los derechos fundamentales han sido una construcción que no solo obedece al Estado, sino que en virtud del Bloque de Constitucionalidad, muchos han sido incorporados en razón a los tratados internacionales sobre derechos fundamentales. Al respecto ver: Declaración Universal de los Derechos Humanos 1948; Pactos Internacionales de 1966; Convenciones Internacionales Sobre Derechos Humanos.
De este artículo se desprenden las metas u objetivos hacia los cuales debe "caminar" el Estado Social de Derecho. Son estos el oriente de todo cuerpo normativo o actuación administrativa dentro de nuestro territorio nacional y, además, deben ser el móvil inherente al Estado en todas las actuaciones de sus entidades o servidores públicos (De más está señalar que dicha obligación también compete a los particulares).

Gran problema origina la interpretación de dichos fines, pues la definición de los mismos no es algo que se pueda decir al unísono. Basta con preguntarse ¿Qué es interés general?, y además de ello si dicha definición depende de circunstancias tales como el modelo económico de un país.

Hechas las anteriores apreciaciones, y en pro de dar una mayor claridad al asunto del presente artículo, el desarrollo que daremos a los principios será en el siguiente orden: 1.) Principios Constitucionales; 2.) Principios Legales. De este modo descenderemos y entenderemos la forma en que se articulan dichos principios, para con posterioridad a ello, dar una correcta interpretación al cuerpo normativo que integra el sector minero.

\subsection{Principios Constitucionales}

Debe hacerse la aclaración que para el presente caso se señalaran únicamente los principios relevantes en lo que se refiere a la inseguridad jurídica de que trata la temática principal. Por lo anterior, principios tales como la igualdad, la moralidad, la eficacia, la economía, la celeridad etc. no serán tratados para estos efectos, a pesar de que son relevantes en cuanto al desarrollo de la actividad extractiva en general.

\subsubsection{El Estado Social de derecho}

Uno de los principios más importantes es el que señala que "Colombia es un Estado Social de Derecho". Prima facie, dicho concepto no entraña mayor complejidad; más si nos adentramos en sus implicaciones, veremos que en realidad trae varios retos, al menos para el desarrollo de la industria extractiva.

Para entender los efectos de dicho concepto realizaremos una segmentación del mismo. En primer lugar, tenemos el Estado, cuya concepción la abordaremos desde la actual interpretación de la Corte Constitucional. 
Debe decirse para comenzar que la concepción de "Estado" como "Nación" se ha reevaluado; con la integración de conceptos como la autonomía administrativa y descentralización se ha entendido que si bien es cierto, a la luz de los artículos 332 y 334 de la Constitución Política, se ha dado preponderancia a la Nación en lo que se refiere a la explotación de recursos naturales, también lo es que la autodeterminación de los municipios y departamentos -en aplicación de los principios de concurrencia y coordinación- es fundamental a la hora de decidir sobre la explotación de dichos recursos. La razón es que dicha decisión afecta en forma directa los intereses de la población de los territorios.

En términos de la Corte Constitucional:

(...) si bien la interpretación del artículo 37 del Código de Minas puede sustentarse en el principio constitucional de organización unitaria del Estado -artículo 1 de la Constitución- y los contenidos específicos de los artículos 332 y 334 de la Constitución, que privilegian la posición de la Nación en la determinación de las políticas relativas a la explotación de recursos naturales; también_deben tenerse en cuenta otros contenidos constitucionales de igual valía dentro de la organización del Estado, como son los principios de autonomía y descentralización de que gozan las entidades territoriales para la gestión de sus intereses -artículo 287 de la Constitución-, y de coordinación y concurrencia -artículo 288 de la Constitución-, que se deben acatar al hacer el reparto de competencias entre la Nación y, en este caso, los municipios y distritos. (Corte Constitucional, 2014). (Subrayado fuera del texto).

Así, es evidente que la concepción del Estado como un ente centralizado empieza a flexibilizarse, pues en concordancia con los artículos 287 y 288 constitucionales, se entiende que las decisiones deben ser concertadas con los entes territoriales también. Dicha concepción obedece a la incorporación de los derechos colectivos dentro de nuestra Constitución Política y además, a la salvaguarda de un orden justo, al tenor del artículo primero de la Constitución Política de 1991. En este sentido continúa la Corte diciendo:

Por esta razón, y en procura de una solución que permita aplicar de forma armónica el contenido de los principios que se encuentran en tensión en este caso concreto, se concluye que el artículo 37 de la Ley 685 de 2001 -Código de Minas- estará acorde con la Constitución, siempre y cuando en el proceso de autorización para la realización de actividades de exploración y explotación minera -cualquiera sea el nombre que se dé al procedimiento para expedir dicha autorización por parte del Estado- se tengan en cuenta los aspectos de coordinación y concurrencia, los cuales se fundan en el principio constitucional de autonomía territorial. En este sentido, una autorización al respecto deberá dar la oportunidad de participar activa y eficazmente a las entidades municipales o distritales involucradas en dicho proceso, mediante acuerdos sobre la protección de cuencas hídricas y la salubridad de la población, así como, del desarrollo económico, social y cultural de sus comunidades (Corte Constitucional, 2014). (Subrayado fuera del texto).

Entonces, el Estado debe entenderse como el conjunto de todas las entidades territoriales en el nivel nacional, departamental y municipal. Tesis que resulta compleja bajo los lineamientos normativos que nos dicta la Ley 685 de $2001^{8}$, pues es claro su eminente contenido centralista.

Ahora bien, una vez identificada la nueva concepción de Estado, debemos desarrollar la segunda característica, es decir la de "Social". Para comenzar, debemos mencionar que es una de las mayores conquistas de nuestra Constitución Política de 1991, pues sólo bajo una nueva óptica del derecho y de la sociedad, se comenzó a gestar la categoría de "derechos sociales", de los cuales emana también el derecho a un "medio ambiente sano" y, en fin, a todos aquellos que afectan en forma directa la vida y salud de los habitantes en comunidad.

Para hablar del Estado "Social", en primera medida debemos abarcar el concepto de social en varias de sus más importantes acepciones doctrinales. En criterio personal, la concepción sub examine comporta uno de los fenómenos propios de la mutación de los derechos humanos, es decir, en la medida en que se avanza en la escala histórica social, dicho concepto se amolda y modifica dependiendo de los nuevos hechos o situaciones de la sociedad.

8. Conocida como Código de Minas. 
Para Pérez, 1991, "La mutación histórica de los derechos fundamentales ha determinado la sucesiva aparición de sucesivas generaciones de derechos" (p. 205) por lo que es natural que, con el paso del tiempo, la concepción individualista de los derechos humanos se haya extendido a la categoría de grupo. En este orden de ideas para Pérez, 1999, los derechos humanos (primera categoría) más los derechos económicos, sociales y culturales (segunda categoría), implicaron el cambio de un Estado Liberal de Derecho por un Estado Social de Derecho.

A partir de la concepción de Colombia como una república libre y democrática se puede entender la nueva articulación de derechos sociales tal y como lo vemos ahora. Cuando una sociedad es recipiendaria de derechos fundamentales, se hace más sensible y progresista en lo que atiene a la obtención y salvaguarda del interés general, por ello, la conciencia social evolucionada le conmina a la creación de artificios legales que custodien en mayor grado sus intereses como grupo. De allí que el paradigma para el siglo XXI le haya impuesto la carga social a todas las actividades que se desarrollen en el territorio nacional, inclusive las del campo individual (como lo es la actividad extractiva).

Entendido lo anterior, podemos concluir que el desarrollo de los derechos fundamentales ha decantado en una nueva concepción del derecho en general, y por ello, todo lo que él regula, tendrá que incluir en sí una responsabilidad social característica del estado social de derecho-. La incorporación de esta nueva óptica en la jurisprudencia, por lo menos a nivel contractual, ha hecho que se generen nuevos retos, tendientes a la armonización de los derechos fundamentales y los derechos contractuales o económicos, pues en ningún caso, pueden éstos últimos cercenar los primeros bajo la justificación de un lucro indolente con la sociedad.

\subsubsection{La autonomía territorial}

El artículo primero, del Título primero, de la Constitución Política de Colombia 1991 señala:

Colombia es un Estado Social de derecho, organizado en forma de República unitaria, descentralizada, con autonomía de sus entidades territoriales, democrática, participativa y pluralista, fundada en el respeto de la dignidad humana, en el trabajo y la solidaridad de las personas que la integran y en la prevalencia del interés general.

Dicho concepto ha venido variando de conformidad con la interpretación de la Corte Constitucional en el entendido en que dicha autonomía se ha ampliado, al punto en que ahora, en virtud de la protección del medio ambiente, en el proceso de reglamentación del suelo se puede inclusive, llegar a prohibir por consenso grupal, la actividad minera (o de cualquier naturaleza) en cualquier territorio.

Dicha concepción de la autonomía ha sentado un nuevo derrotero, un cambio de paradigma, dentro de la interpretación constitucional. Se ha entendido que la autonomía territorial es un principio que ayuda en el proceso de materialización de los postulados constitucionales; de ahí que la activa participación de las comunidades resulte importante en los eventos en que se toman determinaciones (por lo general del orden central) que afectan en forma directa el medio ambiente. Lo anterior obedece a una lógica en la que son ellas -las comunidades- quienes conocen a profundidad las particularidades de su territorio y, por ende, cuentan con la legitimidad y capacidad suficiente como para prever las consecuencias que puede traer consigo cualquier actividad en su región y en el futuro de sus familias y comunidad.

En materia de derecho constitucional se ha reconocido que la autonomía de las entidades territoriales, al tenor de los artículos $1^{\circ}$ y $287^{\circ \circ}$ de la Constitución Política de 1991, es fundamental para lograr una correcta gestión de sus intereses, y además, se puede decir que ésta en realidad implica la verdadera consecución de la protección de los derechos fundamentales tanto subjetivos como colectivos.

9. Señala: Artículo 287: "Las entidades territoriales gozan de autonomía para la gestión de sus intereses, y dentro de los límites de la Constitución y la ley. En tal virtud tendrán los siguientes derechos: 1. Gobernarse por autoridades propias. 2. Ejercer las competencias que les correspondan. 3. Administrar los recursos y establecer los tributos necesarios para el cumplimiento de sus funciones. 4. Participar en las rentas nacionales." (Subrayado fuera del texto). Debe entenderse que la administración de recursos no se limita únicamente a los de orden económico, también obedece a la capacidad que tienen las entidades territoriales para organizar el territorio propendiendo por conseguir un mejor aprovechamiento de los recursos renovables y no renovables existentes en su territorio. De más está decir que dicho aprovechamiento debe tener como oriente la satisfacción de los derechos de quienes integran dicha comunidad. 
La doctrina ha previsto que uno de los principales requisitos para la consecución de la paz es el respeto por la autodeterminación de los pueblos. Dicha autodeterminación para el presente artículo deberá entenderse como la garantía de protección al medio ambiente en que las comunidades desarrollan su vida. En forma acertada Ferrajoli, 2013, señala que en ningún caso podrá privarse a un pueblo de sus propios medios de subsistencia y es ahí, donde la garantía de autodeterminación puede llegar a mutar y evolucionar al punto en que -por lo menos en cuanto a la industria extractiva- puedan prohibirse el desarrollo de actividades económicas que afectan sus derechos colectivos y además, ponen en riesgo los de las futuras generaciones.

Frente al actual conflicto que vivimos en Colombia -relacionado con el desarrollo de la actividad extractiva dentro de los municipios $\mathrm{y}$, la presunta afectación de derechos colectivos-, Ferrajoli (2013) nos da una luz al señalar dos premisas, a saber: (i) Que en la actualidad, el Estado ha entrado en conflicto con el pueblo, convirtiéndose en una fuente permanente de guerra, y (ii) Que el derecho a la autodeterminación externa es el derecho a la "autonomía", la cual consiste en disponer de las propias riquezas, recursos naturales y a no ser privados de los propios medios de subsistencia. Así, se debe señalar que dichas premisas se han materializado, y que a la postre, nuestro sistema debe mutar para adaptarse a los nuevos retos. A criterio del autor -y a propósito de la autonomía territorial- unos de los más importantes son (i) El cambio de nuestra concepción de Estado ${ }^{10}$ por uno federado y (ii) La implementación de un proceso en Mejora Regulatoria.

En este orden de ideas, es pertinente que señalemos el estado del arte en materia jurisprudencial. Para ello la Corte Constitucional ha hecho un análisis en lo que respecta a la concepción de la autonomía territorial dentro de un estado unitario. Comienza la Corte señalando la forma en que tendría que concebirse la autonomía territorial, pues a raíz de la figura de Estado Unitario, dicho concepto tiene límites, veamos. Ferrajoli,

10. A criterio de FERRAJOLI, el Estado no es más que el último legado envenenado de la colonización.
Sin embargo, en diversas ocasiones la jurisprudencia constitucional ha recordado que los contenidos que integran el principio de autonomía territorial no pueden ser entendidos de forma aislada o descontextualizada, por lo que se hace preceptivo que su concreción en casos particulares atienda otros contenidos del sistema constitucional colombiano. Por esta razón, la interpretación de las posibilidades o ámbitos en que se desarrolla la autonomía territorial no puede desconocer que las instituciones, procedimientos y las competencias que la concretan existen y se desarrollan en un Estado que, de acuerdo con el artículo 1 de la Constitución, ha adoptado una forma de organización territorial unitaria, es decir, no puede olvidarse que el colombiano es un Estado unitario en lo relativo al principio de organización territorial (Ferrajoli, 2013: 8). (Subrayado fuera del texto).

Así, se empiezan a ver los primeros retos a superar a partir de esta concepción, por lo menos en lo que atiene a la potestad para conferir títulos mineros y a las competencias que tienen cada uno de los órganos descentralizados de la administración pública. Por un lado, la legislación minera (Ley 685 de 2001) confiere potestades al orden central para disponer libremente del subsuelo, pues, se entiende que los recursos que yacen en el subsuelo son de propiedad del Estado, y de otro, los demás órganos de Estado (con competencias sobre la materia ${ }^{11}$, es decir, la extractiva ${ }^{12}$ ) tendrán que coordinar la actividad que desarrolla la autoridad minera con lo que es de su competencia, para que de este modo pueda llegar a desarrollarse dicha actividad extractiva en armonía con los postulados constitucionales y legales.

El concepto de autonomía territorial como hemos visto, entraña un sinfín de complicaciones en lo que atañe a su interpretación dentro de un Estado Unitario como lo señala el artículo primero constitucional. Dicha interpretación es fundamental para el caso que nos atañe; más

11. Puede entenderse que dichas competencias no sólo se limitan a la concesión del subsuelo, sino que además involucra las obligaciones de índole ambiental y de garantizar los derechos fundamentales de las poblaciones. Así, vemos que existe una cruzada de competencias sobre el mismo asunto, en los diferentes momentos de las concesiones mineras

12. Entendamos éstas como los entes territoriales y las autoridades en materia ambiental. 
aún cuando de seguridad jurídica se habla. El reconocimiento que se le ha dado a la autonomía territorial en el actual contexto jurisprudencial entraña una serie de cambios que afectan de forma directa el desarrollo de actividades económicas como lo es la minera, por ello, debe tenerse claridad en este momento lo que por autonomía se entiende a la luz del principio de unidad. En este sentido la Corte Constitucional ha dicho:

Ese diseño constitucional implica, entonces, la necesidad de armonizar los principios de unidad y de autonomía, que se encuentran en tensión. Para lograr esto la Corte ha reconocido la existencia de un sistema de limitaciones recíprocas, en el que el concepto de autonomía territorial se encuentra restringido por el de unidad, y a la inversa, la unidad se encuentra circunscrita ${ }^{13}$ por el núcleo esencial de la autonomía. Por tal motivo, la interpretación y aplicación de estos principios debe estar encaminada a obtener su pleno equilibrio y coexistencia, sin que ninguno de ellos sea absoluto en perjuicio del otro: el concepto de unidad del Estado colombiano no puede ser utilizado como pretexto para desconocer la capacidad de autogestión de las entidades territoriales, y a su turno, la autonomía de las entidades territoriales no puede ser entendida de manera omnímoda, hasta el punto de hacer nugatorias las competencias naturales de las instancias territoriales centrales (Corte Constitucional, 2016). (Subrayado y negrillas fuera del texto).

Así, en virtud de la autogestión de los entes territoriales, se empieza a morigerar un poco el concepto de estado unitario. Señalar lo anterior tiene gran relevancia pues, es a raíz de esta afirmación que en la actualidad, los entes territoriales y/o las comunidades en general, han quedado legitimadas para que en uso de las acciones constitucionales (para el caso en concreto, la acción popular) prohíban o, siquiera hagan un esfuerzo por prohibir el desarrollo de una actividad económica como lo es la minería.

13. Gran luz proporciona ésta palabra subrayada en el fallo, se señala que dentro del sistema de límites, es el principio de Unidad el cual debe circunscribirse a los límites que impone el principio de autonomía territorial. Por lo que es evidente la prevalencia del principio de autonomía territorial sobre el de unidad, a pesar de que más adelante se señale que ambos se encuentran en pleno equilibrio y coexistencia.
De lo anterior se colige que esta situación per se constituye una fuente de inseguridad jurídica para la inversión, al menos en este sector. El sustento de dicha idea es que la inversión que se realiza en la industria extractiva ya no solo depende de las variables económicas del mercado, sino que además, depende de la voluntad de los pueblos; por ello, el éxito o fracaso de un proyecto minero ${ }^{14}$ está supeditado al tipo de acuerdo al que se llegue con las comunidades.

Ahora bien, la capacidad de autodeterminación de los pueblos -autonomía- no debe tomarse solamente como un elemento mediante el cual se ha flexibilizado la concepción de estado unitario -desde la esfera de los fundamentos axiológicos de los dos principios en comento-, sino que además de ello, debemos tener en cuenta el fundamento práctico que da sustento a la prevalencia de ésta autonomía, pues es con base en esteel fundamento práctico- que se han podido vislumbrar los efectos colaterales negativos propios de la actividad extractiva. En buena hora ha dicho la doctrina colombiana que:

En el marco de las actividades que componen la operación minera, las empresas están en riesgo de incurrir en impactos negativos o violaciones a derechos humanos, y del mismo modo pueden acarrear el compromiso de su responsabilidad civil, administrativa o incluso penal por estos hechos (Guiza, 2016:601).

Así pues, dicha autonomía resulta en una herramienta útil a la hora de tomar decisiones que decanten en la protección de los derechos fundamentales subjetivos y colectivos.

Finalmente, advierte el autor que los nuevos cambios jurisprudenciales y de paradigma -en cuanto a la concepción de estado unitario y de autonomía- nos ubican en un escenario en el cual debe darse un nuevo trato a la regulación en materia minera. En la actualidad no basta con el cumplimiento de unos requisitos formales para la obtención de un título de concesión minero y con él, el inicio de una actividad extractiva; sino que por el contrario, ahora, deberá

14. Además de ello, es bueno recordar que en virtud a la falta de coordinación entre las autoridades -tanto ambientales como minera y de hidrocarburos-y de las nuevas directrices del Gobierno Nacional (en lo que respecta a la delimitación de páramos) 
regularse teniendo en consideración el papel preponderante que juegan las comunidades a la hora de tomar una determinación que pudiera llegar a afectar sus intereses comunitarios y además, los del medio ambiente.

\subsection{Principios legales}

Para dar desarrollo a los principios legales, deberemos puntualizar que para el presente escrito nos limitaremos únicamente a los contenidos en la Ley 685 de 2001 (Código de Minas), y además, los que directamente se relacionen con la problemática general. Sólo de este modo podremos vislumbrar el fenómeno de inseguridad jurídica que se presenta para el sector minero a partir de la interpretación de los artículos 36 y 46 de la misma norma.

El artículo 36 señala en primera medida lo siguiente:

En los contratos de concesión se entenderán excluidas o restringidas de pleno derecho, las zonas, terrenos y trayectos en los cuales, de conformidad con los artículos anteriores, está prohibida la actividad minera o se entenderá condicionada a la obtención de permisos o autorizaciones especiales. Esta exclusión o restricción no requerirá ser declarada por autoridad alguna, ni de mención expresa en los actos y contratos, ni de renuncia del proponente o concesionario a las mencionadas zonas y terrenos. Si de hecho dichas zonas $\mathrm{y}$ terrenos fueren ocupados por obras o labores del concesionario, la autoridad minera ordenara su inmediato retiro y desalojo, sin pago, compensación o indemnización alguna por esta causa ${ }^{15}$. Lo anterior, sin perjuicio de las actuaciones que inicien las autoridades competentes en cada caso cuando a ello hubiere lugar (Ley 685, 2001). (Subrayado fuera del texto).

Debe señalarse a modo de crítica, que del artículo en cita, el aparte subrayado resulta ser una medida arbitraria pues desconoce los derechos

15. Gran problemática genera la expresión señalada toda vez que con el nuevo procedimiento para la delimitación de páramos se ha anulado el derecho de los titulares mineros, quienes con anterioridad a la fecha de declaratoria del páramo obtuvieron en forma legal su título. De ahí, que la inversión realizada por los empresarios mineros se vea hoy en riesgo, pues al no reconocerse prestación económica alguna, se viola en forma arbitraria sus derechos y además, se produce un daño económico de grandes dimensiones. económicos de los concesionarios mineros; la razón es que en muchas de las ocasiones dicha declaratoria no obedece únicamente a los eventos de los artículos anteriores a este artículo 36, sino que además obedece a una situación unilateral (como lo es la declaratoria de las zonas de páramo ${ }^{16}$ ) que no puede ser previsible ni mucho menos se encuentra en la esfera de los aleas normales dentro de la actividad económica.

Ahora veamos lo consagrado en el artículo 46 de la Ley 685 de 2001:

Normatividad del contrato. Al contrato de concesión le serán aplicables durante el término de su ejecución y durante sus prorrogas, las leyes mineras vigentes al tiempo de su perfeccionamiento, sin excepción o salvedad alguna. Si dichas leyes fueren modificadas o adicionadas con posterioridad, al concesionario le serán aplicables estas últimas en cuanto amplien, confirmen $o$ mejoren sus prerrogativas exceptuando aquellas que prevean modificaciones de las contraprestaciones económicas previstas en favor del Estado o de las de Entidades Territoriales. (Subrayado fuera del texto).

Al tenor literal de la expresión subrayada podemos señalar que al contrato de concesión minera se le aplicó por mandato legal un principio de favorabilidad, que en a la luz de la Constitución Política de 1991 tiene mucho sentido y, además, se complementa en virtud del principio de progresividad ${ }^{17}$ según el cual: el artículo 4 del Pacto Internacional sobre Derechos Económicos, Sociales y Culturales (PIDES).

(...) Este principio se construyó a partir del alcance de las obligaciones de los estados parte del Protocolo Internacional de Derechos Económicos, Sociales y Culturales de la ONU y, de la misma manera, se consideró

16. Muy a pesar de las concertaciones que por mandato legal y jurisprudencial deben realizarse tanto con las poblaciones que se vean afectadas por dicha delimitación, como con los sectores económicos o industriales que vean en riesgo sus derechos.

17. Principio ampliamente abarcado en el artículo $4^{\circ}$ del Pacto Internacional sobre Derechos Económicos, Sociales y Culturales (PIDESC). Señala: "Los Estados Partes en el presente Pacto reconocen que, en ejercicio de los derechos garantizados conforme al presente Pacto por el Estado, éste podrá someter tales derechos únicamente a limitaciones determinadas por ley sólo en la medida compatible con la naturaleza de esos derechos y con el exclusivo objeto de promover el bienestar general en una sociedad democrática." 
aplicable en el ámbito interno a los "derechos sociales", bajo la doctrina tradicional de las "generaciones" de derechos. Sin embargo, como se desprende de lo expuesto hasta el momento, todos los derechos tienen contenidos de carácter positivo y negativo, razón por la cual el principio sería aplicable también a las facetas positivas de los derechos tradicionalmente considerados civiles y políticos, cuya aplicación inmediata suele considerarse fuera de discusión.

(...) Elúltimo aspecto, denominado prohibición de regresividad o prohibición de retroceso, se desprende de forma inmediata del mandato de progresividad $\mathrm{y}$, de manera más amplia, del principio de interdicción de arbitrariedad, propio del Estado de Derecho: si un Estado se compromete en el orden internacional y constitucional a ampliar gradualmente la eficacia de los contenidos prestacionales de los derechos constitucionales, resulta arbitrario que decida retroceder en ese esfuerzo de manera deliberada (Corte Constitucional, 2015). (Subrayado fuera del texto).

Prima facie podríamos pensar que el criterio de la Corte Constitucional en materia de derechos económicos aplica en forma perenne la estructura del principio de progresividad, más no es así. Dicho principio encuentra sus límites interpretativos cuando en virtud de la violación al principio de no regresividad se pretende salvaguardar derechos de primer categoría, o los que mediante un test de ponderación ${ }^{18}$ prevalezcan sobre los derechos económicos. La Corte ha señalado:

(...) Sin embargo, esta Corporación ha considerado, en armonía con la doctrina autorizada del DIDH, que no toda regresión es arbitraria, pues la adecuada utilización de los recursos públicos y las necesidades más apremiantes que en cada momento enfrenta el Estado en materia social, pueden llevar a considerar como constitucionalmente válida o legítima la modificación de políticas públicas y normas jurídicas que impliquen un retroceso en la eficacia de un derecho, si esas medidas

18. Ponderación que a criterio del autor sigue conservando un criterio subjetivo del juzgador. Criterio que depende de las construcciones morales de la época, y que de por sí, volatiliza el precedente judicial pues con base en nuevos elementos sociales modifica las decisiones. comportan a la vez una ampliación (de mayor importancia) del ámbito de protección de otro u otros derechos.

\section{(...)}

Por esta razón, la prohibición de regresividad no es absoluta. La validez de normas, medidas o políticas regresivas en materia de derechos constitucionales está sometida a los principios de razonabilidad y proporcionalidad, bajo parámetros ya decantados por la jurisprudencia constitucional (Corte Constitucional, 2015). (Subrayado fuera del texto).

A partir de las expresiones subrayadas cabe preguntarnos ¿Acaso dicha flexibilidad en la prohibición de regresividad aplica para las prestaciones de un contrato de concesión minera que se celebró a la luz de una normatividad y contexto legal que no contempló que de forma unilateral el Estado pudiera excluir el desarrollo de una actividad económica?, es más, ¿Qué tan arbitrario resulta que con base en declaraciones posteriores (Como lo es la declaratoria de páramo) se cercenen los derechos de un empresario minero, al suspenderle en forma súbita la ejecución de su contrato y además de ello, no reconocerle prestación alguna por los trabajos y obras realizados en dicho proyecto?

Es evidente que dicho precepto viola en forma flagrante los derechos económicos del inversionista, o por lo menos pone en tela de juicio el concepto de seguridad jurídica en lo atinente a la inversión. Lo anterior porque si bien es cierto, el concesionario minero debe respetar la nueva zona declarada como páramo ${ }^{19}$, también lo es, que tiene derecho a percibir una indemnización por la finalización arbitraria en la ejecución de su contrato por culpa de la decisión unilateral de la administración pública.

Ahora bien, para continuar con el principio de favorabilidad -que podemos ver es aplicable al contrato de concesión minera-, debemos resaltar uno de los apartes del artículo 46 de la Ley 685 de 2001 el cual señala que "Si dichas leyes fueren modificadas o adicionadas con posterioridad, al concesionario le serán aplicables estas últimas en cuanto amplíen, confirmen o mejoren sus

19. Declaración que pretende la salvaguarda del interés colectivo al medio ambiente. 
prerrogativas". Así, queda en evidencia la clara voluntad del legislador de salvaguardar las prerrogativas que con el contrato de concesión se obtuvieron, es decir, las económicas; tanto es así que la misma ley señala que sólo para efectos de las contraprestaciones en favor del $\operatorname{Estado}^{20}$ no le será aplicable dicha regla.

De lo dicho hasta ahora podemos decir que el legislador previó un régimen legal garantista y respetuoso de la inversión. A raíz de esta tesis se concesionaron varios polígonos en el país, sobre los cuales se comenzó a realizar las obras de exploración y luego, los de explotación. En muchos de esos polígonos únicamente se tuvo en cuenta las prohibiciones que por mandato de la ley -para aquella época- le eran aplicables, más ahora, bajo una nueva óptica en la política medio ambiental, se han llegado a crear afectaciones en áreas que en el pasado no se habría pensado fueran posibles ${ }^{21}$.

\section{DESARROLLO JURISPRUDENCIAL}

Ahora bien, decantado el contenido legal $y$ de principios que rodean la temática principal del artículo, se comenzará a señalar los pronunciamientos jurisprudenciales más relevantes en cuanto a la aplicación de los principios vistos.

\footnotetext{
20. Regalías e impuestos.

21. Sobre dicha problemática se puede decir además que afecta todo tipo de actividad económica que se desarrolle en las zonas declaradas como páramos. Al respecto vale citar un aparte de la revista SEMANA en donde se señala:

Para Ivonne González, vocera de Asomusanturbán, la aprobación de la ley no los deja conformes, pues cree que las soluciones planteadas para los pequeños mineros $y$ agrícolas de las regiones no son claras y no salvaguardan la tradición de los pueblos. "Pareciera que estuvieran haciendo leyes contra la industria y no les importa llevarse a personas como nosotros que tenemos más de 400 años trabajando en el territorio", dijo y agregó que "quedamos desconcertados con lo que pueda pasar con nosotros, ahora debemos estar pendientes de cómo vaya a reglamentar el gobierno entrante esta ley". (SEMANA, 2018).

Así queda otro de los muchos resultados decantado, la afectación a los empleos de muchas personas es evidente y además de ello, casi toda la afectación que se sufre es en materia económica, ya que no sólo se les prohíbe el desarrollo de una actividad a la que estaban habituados, sino que además, -como reto del Gobierno nacional- se les debe hacer una transición a otras fuentes de ingreso que supla sus mínimos. Ahora, cabe preguntarse ¿será que dicha nueva actividad económica, en forma real y efectiva, podrá suplir las necesidades de la población sin desmejorar su calidad de vida?, es decir, ¿percibirán los mismos ingresos con la nueva actividad que con la anterior que fue prohibida? Mucho queda aún por articular.
}

Inicialmente, y en virtud de dar un orden cronológico adecuado a lo que hasta ahora constituye el derrotero jurisprudencial para la materia, debemos mencionar la sentencia de la Corte Constitucional, 2014, en la cual se desarrolla por primera vez una controversia entre la reglamentación del uso del suelo por parte de los entes territoriales en ejercicio de la autonomía territorial, y la libre disposición con la que cuenta el Gobierno central para administrar de las riquezas del subsuelo, en ejercicio del principio de Estado Unitario. A pesar que sobre dicho caso se intentó demostrar una presunta cosa juzgada ${ }^{22}$, dicha excepción no prosperó, luego entonces es del caso observar lo que de contenido tiene dicha sentencia.

La aventurada conclusión de la Sala fue que entre los organismos del orden central y los descentralizados (v.g. Gobernaciones, Municipios) debe existir una armonía en el ejercicio de sus actividades administrativas. Así es que, los principios de Concurrencia, Coordinación y Subsidiariedad constitucionales deben tener plena aplicación en el ejercicio administrativo de los entes de cualquier orden, más aún cuando de conceder derechos sobre el subsuelo se trata; pues con dicha concesión de derechos se puede impactar la calidad de vida de la población.

Dicha sentencia de constitucionalidad evalúa en forma juiciosa los principios que entran aparentemente en contradicción. En primer lugar desarrolla el papel que juega el ordenamiento del territorio $^{23}$ en la salvaguarda y promoción del medio ambiente. Así, señala:

22. En las intervenciones realizadas durante el proceso, debemos destacar las del Ministerio de Minas y Energía (MME), la Agencia Nacional de Minería (ANM), y la Asociación Naciona de Empresarios de Colombia (ANDI); pues en ellas se alegó la existencia de cosa juzgada; excepción que para el caso no prosperó. Si bien es cierto, citaron como precedente sobre la materia a la Sentencia C-395 de 2012, también lo es que: "En primer lugar debe aclararse que, aunque el artículo acusado es el mismo en uno y otro caso al momento de tomar la decisión plasmada en la Sentencia C-395 de 2012 se encontraba vigente la ley 1382 de 2010, cuerpo normativo que, si bien no modificó el artículo 37 del Código de Minas, subrogó disposiciones determinantes para la interpretación del mismo, como son el artículo 34 y 38 del mismo cuerpo normativo. Esto conlleva a que el sentido normativo derivado del artículo 37 en vigencia de la ley 1382 de 2010 se viera afectado por el contenido normativo de preceptos que, al momento en que se toma esta decisión, ya no se encuentran vigentes" (Subrayado fuera del texto). (Corte Constitucional, 2014).

23. Ordenamiento que desarrollan los entes territoriales mediante los Planes de Ordenamiento Territorial (POT). 
La simple existencia de una regulación nacional que establezca límites a la facultad de reglamentar los usos del suelo por parte de los municipios no implica per se vulneración del principio de autonomía territorial. Por el contrario, esta parece ser la opción contenida en la Constitución, que i) en su artículo 288 prevé que la gestión de sus intereses por parte de, entre otros, los municipios debe hacerse dentro de los límites de la Constitución y la ley; ii) que determina que, más que regular, los consejos municipales reglamentarán los usos del suelo, reglamentación que, como es obvio, debe hacerse en acuerdo con la regulación legal existente artículos 311 y 313 numeral 7-; iii) que prevé que la distribución de competencias se hará en los términos en que se establezca la ley -artículo 288; iv) que asigna la propiedad del subsuelo al Estado -artículo 332-; v) que asigna la propiedad de los recursos naturales al Estado -artículo 332-; vi) que determina que la intervención del Estado en la economía debe seguir los parámetros establecidos en la ley -artículo 334; y vii) que dicha intervención debe tener como objetivo el mejoramiento de la calidad de vida de los habitantes del territorio. De manera que el propio constituyente determinó que la ley fuera la norma a partir de la cual i) se desarrollara el contenido del principio de autonomía que ahora se considera vulnerado; y la norma a partir de la cual ii) se diera el desarrollo de los parámetros de intervención del Estado en materia de exploración y explotación minera, regulación que busca un objetivo legítimo, como es el mejoramiento de la calidad de vida de los habitantes del territorio. En este sentido, resulta acorde con la organización unitaria del Estado que exista unificación en los criterios, procesos y parámetros que permiten obtener la autorización por parte de la administración para desarrollar actividades de exploración y explotación minera -cualquiera sea el nombre que se dé al procedimiento para expedir dicha autorización por parte del Estado-. Adicionalmente, es acorde con el principio de organización unitaria del Estado que los lugares en que dichas actividades pueden realizarse $y$, en consecuencia, los criterios para la exclusión de un determinado territorio de la actividad minera sean determinados por una misma entidad, siguiendo idénticos criterios para todo el territorio del Estado. (Corte Constitucional, 2014). (Subrayado y negrilla fuera del texto original).
Así, comienza la Corte a aventurarse por las sendas conflictivas que representa la capacidad de reglamentación el uso del suelo en cabeza de los municipios $^{24}$ junto con las potestades que tiene el gobierno central para administrar lo que es suyo, es decir, el subsuelo ${ }^{25}$.

Sobre este problema la Corte Constitucional continuó con la ardua labor de intentar resolver el conflicto. La postura de los últimos fallos tuvo una posición claramente proteccionista de la autonomía de los entes territoriales. Dentro de los fallos con una parte considerativa bastante polémica podemos encontrar -continuando con el orden cronológico-, la sentencia con radicado T-445 de 2016, Sentencia que a pesar de ser de tutela $^{26}$ deja un precedente importante.

La tesis de dicha sentencia sostiene que con base en la autonomía que tienen los entes territoriales para desarrollar su vida en sociedad y propender por el bienestar de la comunidad, puede organizar su territorio de tal forma que es posible excluir el desarrollo de la actividad minera de sus territorios ${ }^{27}$. Muchos puntos positivos se

\section{En ejercicio de su autonomía territorial.}

25. De conformidad con el artículo 332 de la Constitución de 1.991. No perdamos de vista que dicha tesis ha tenido un desarrollo histórico en el que el subsuelo pasó por ser, en primera medida, propiedad de particulares, y luego, durante el mando de Simón Bolívar, dicha propiedad se nacionalizó; a partir de ello comenzó una disputa -que hasta el día de hoy tiene sus rezagos- entre los "estados soberanos" de 1958 y la "Nación". A criterio del autor, dicho conflicto encontró su "pseudo - solución" en el artículo 1 de la Constitución Política de 1.991, pues en éste se incorporó al mismo rango, tanto la cláusula de estado unitario como la de autonomía de los entes territoriales. Al ser de éste modo, vemos que dichas clausulas en el desarrollo jurisprudencial de la Corte Constitucional han chocado, a pesar de que se conmine a una coordinación entre el orden central y los entes territoriales.

26. Éste tipo de Sentencias tiene efectos inter partes.

27. Postura absolutamente discutible en el entendido de que esta riñe con postulados como lo es la libertad de empresa y las potestades de un estado unitario. Al respecto, el artículo 333 de la Constitución señala: "Artículo 333. La actividad económica y la iniciativa privada son libres, dentro de los límites del bien común. Para su ejercicio, nadie podrá exigir permisos previos ni requisitos, sin autorización de la ley. La libre competencia económica es un derecho de todos que supone responsabilidades. La empresa, como base del desarrollo, tiene una función social que implica obligaciones. El Estado fortalecerá las organizaciones solidarias y estimulará el desarrollo empresarial. El Estado, por mandato de la ley, impedirá que se obstruya o se restrinja la libertad económica y evitará o controlará cualquier abuso que personas o empresas hagan de su posición dominante en el mercado nacional. La ley delimitará el alcance de la libertad económica cuando así lo exijan el interés social, el ambiente y el patrimonio cultural de la Nación." (Subrayado fuera del texto). Por lo anterior, no es comprensible cómo, de tajo, los entes territoriales sin realizar concertación alguna con el sector industrial, pueden llegar a prohibir el desarrollo de una 
ven en la sentencia en cita, pero así mismo, es claro que se originan muchos problemas por la posibilidad de exclusión de la que habla.

Dentro de los puntos positivos que desarrolla la sentencia, podemos encontrar los reseñados anteriormente en la Sentencia C-123 de 2014, es decir, los principios de concurrencia, coordinación y subsidiariedad. Dicha sentencia los define de la siguiente forma:

El principio de concurrencia parte de la consideración de que, en determinadas materias, la actividad del Estado debe cumplirse con la participación de los distintos niveles de la administración. Ello implica, en primer lugar, un criterio de distribución de competencias conforme al cual las mismas deben atribuirse a distintos órganos, de manera que se garantice el objeto propio de la acción estatal, sin que sea posible la exclusión de entidades que, en razón de la materia estén llamadas a participar. La Sentencia C-123 de 2014 sobre el particular, precisó: «De este principio, por otra parte, se deriva también un mandato conforme al cual las distintas instancias del Estado deben actuar allí donde su presencia sea necesaria para la adecuada satisfacción de sus fines, sin que puedan sustraerse de esa responsabilidad». (Corte Constitucional, 2014) (Subrayado fuera del texto).

Así, podemos señalar que la concurrencia es la facultad (y deber) que tienen los diferentes órganos del estado para participar en la toma de decisiones que involucren sus competencias. Ahora bien, debemos preguntarnos si con el ejercicio unilateral que implica la acción popular ${ }^{28}$, se está o no garantizando dicha concurrencia, más aún cuando en uso de este medio constitucional lo que se pretende, es prohibir de plano el desarrollo de una actividad que se encuentra en cabeza de un órgano del estado; para el caso en concreto es el desarrollo de la actividad minera cuya competencia, administración y control, recae en cabeza de la Agencia Nacional de Minería.

actividad extractiva en su territorio, dada cuenta de que es un mandato imperativo de la Constitución el que el Estado debe impedir que se obstruya la libertad económica, y además, evitar restricciones al ejercicio de la actividad económica.

28. Unilateral en el entendido en que la ejerce la población civil sin consideración alguna, o acuerdo previo, con los diferentes órganos del estado que ven afectada la esfera de sus competencias por su iniciativa popular.
Decantado lo anterior continuamos con el desarrollo que dio la sentencia al principio de coordinación:

El principio de coordinación, a su vez, tiene como presupuesto la existencia de competencias concurrentes entre distintas autoridades del Estado, lo cual impone que su ejercicio se haga de manera armónica, de modo que la acción de los distintos órganos resulte complementaria y conducente al logro de los fines de la acción estatal. Esa coordinación debe darse desde el momento mismo de la asignación de competencias y tiene su manifestación más clara en la fase de ejecución de las mismas. En igual medida el Auto 383 de 2010 respecto de este principio afirmó que: «exige la ordenación sistemática, coherente, eficiente y armónica de las actuaciones de los órganos estatales en todos los niveles territoriales para el logro de los fines del Estado» (Corte Constitucional, 2014) (Subrayado fuera del texto).

Entiéndase que el principio de coordinación es un elemento axiológico fundamental en los sistemas de competencias transversales, pues con base en él es que se logra armonizar los diferentes intereses que naturalmente se contraponen en todas las dinámicas sociales y estatales. Respecto de la dinámica estado-individuo debe tenerse en cuenta que "la acción pública se convierte en el producto de interacciones entre protagonistas múltiples, públicos y privados, cuyas estrategias e intereses se pretende conciliar; el contrato es el medio de formalizar esta cooperación" Chevalier, (2011) así, lo que tendría que lograrse a la luz de este principio es una armonía en el ejercicio de las competencias, sustentado en la cooperación y la conciliación entre los diferentes intereses (tanto públicos como privados) que se involucran, acuerdo que además, debe quedar revestido con los elementos de un contrato.

Con base en lo anterior, a criterio del autor, no es de recibo plantear la prohibición de una actividad extractiva como solución; debe procurarse un acuerdo de voluntades, una verdadera concertación, previa conciliación de intereses, para llegar a un verdadero contrato que beneficie a todos los actores. En este sentido, y respecto de la coordinación entre los órganos estatales continúa diciendo que (Chevalier, 2011) "las políticas públicas se caracterizan cada 
vez más por una exigencia de transversalidad, su aplicación supone la intervención de un conjunto de actores públicos, cuya cooperación se formalizará en un dispositivo contractual" (p. 25), de ahí, que además de tener que realizar esfuerzos para conciliar intereses con la población y los activistas sociales, los órganos estatales deberán acordar y cooperar en el desarrollo de sus competencias en forma recíproca, y luchar porque en ningún momento lleguen a cercenar u opacar las competencias del otro. Con la aplicación de ésta fórmula se puede llegar a una gestión institucional eficaz ${ }^{29}$.

Finalmente, la sentencia abarca el principio de subsidiariedad de la siguiente forma:

El principio de subsidiariedad, finalmente, corresponde a un criterio, tanto para la distribución y como para el ejercicio de las competencias. Desde una perspectiva positiva significa que la intervención del Estado, y la correspondiente atribución de competencias, debe realizarse en el nivel más próximo al ciudadano, lo cual es expresión del principio democrático y un criterio de racionalización administrativa, en la medida en que son esas autoridades las que mejor conocen los requerimientos ciudadanos. A su vez, en su dimensión negativa, el principio de subsidiariedad significa que las autoridades de mayor nivel de centralización sólo pueden intervenir en los asuntos propios de las instancias inferiores cuando éstas se muestren incapaces o sean ineficientes para llevar a cabo sus responsabilidades. (Corte Constitucional, 2014) (Subrayado fuera del texto).

Es evidente que, en el desarrollo del principio de subsidiariedad, la Corte Constitucional da una prevalencia a los órganos descentralizados bajo la hipótesis de que son ellos quienes conocen las necesidades de la población. El estudio armónico que desarrolla la Corte sobre los principios de la Constitución Política de Colombia 1991 le lleva a concluir de esa forma.

Ahora bien, no podemos olvidar que dentro del ejercicio de las competencias todos los órganos

29. "ahora bien: este mecanismo de legitimación entró en crisis: la simple invocación del interés general no es ya por sí sola suficiente; es necesario que la gestión pública aporte la prueba de su eficacia" Chevallier, 2011: 25 del Estado, tanto los centralizados como los descentralizados, están llamados a velar por el interés general en su actuar, interés que no solo compete a las regiones o municipios, sino que debe tomarse desde el conjunto de la nación también. Por ello, el principio de Estado unitario toma una dimensión preponderante en la medida de que este asegura la estabilidad del sistema nacional.

Las discrepancias que puedan generarse por el ejercicio de las competencias de los órganos de los distintos órdenes, no necesariamente deben conllevar al cercenamiento o eliminación de competencias de los demás órganos. En este sentido señala Chevallier.

La contractualización de las relaciones Estado y las colectividades territoriales fue así el subproducto de una descentralización que tuvo como efecto no solo el dotar a estas colectividades de una autonomía de acción más extensa, sino también el transferirles amplias atribuciones, dándoles la posibilidad de construir verdaderas "políticas": el recurso a métodos de tipo contractual pasa a ser indispensable para armonizar las acciones conducidas en distintos niveles territoriales. Del mismo modo, el contrato permite contrarrestar los efectos de la especialización funcional, al facilitar el desarrollo de acciones conjuntas. La contractualización aparece como el medio de preservar la cohesión de la acción pública, corrigiendo los efectos del poli centrismo, de la "territorialización" y de la segmentación que afectan a las estructuras estatales; su promoción revela que la concepción monolítica y piramidal del pasado dio paso a una organización más compleja, fundada en el pluralismo y la diversidad, que conlleva el uso de dispositivos más flexibles de coordinación y de armonización (Chevallier, 2011: 35) (Subrayado fuera del texto).

Sobre esta línea de pensamiento se debe decir que, al encontrarnos en un sistema complejo, de competencias varias y distintos intereses, se debe procurar por la armonización de las funciones. Las finalidades del estado siguen siendo las mismas, a pesar de que ahora exista autonomía en los entes territoriales. Sería nefasto para la consecución del bienestar general la idea de entregar prevalencia absoluta y facultades de prohibición a grupos particulares; no se debe perder de vista que estamos en un sistema estatal, y que cualquier mínimo 
desequilibrio del mismo termina por afectar a la colectividad en general, no solamente por regiones.

\section{CONCLUSIÓN Y PROPUESTA}

Entiéndase pues, que armonizar los principios de Estado Unitario y el de Autonomía Territorial es una tarea compleja, máxime cuando de dicha relación depende la seguridad jurídica de un sector $^{30}$. Por ello, la aplicación de los principios de Concurrencia, Coordinación y de Subsidiariedad resulta de imperiosa urgencia. Pero además de lo anterior, debemos ser conscientes de que para dicha aplicación se requiere de un enorme esfuerzo por parte del Gobierno Nacional y de la Rama Legislativa. Profundizando un poco más en el asunto resulta acertado decir que dicha coordinación debe involucrar a las tres Ramas del Poder Público, pues de sus determinaciones depende tanto el rumbo de la industria nacional, como el de las comunidades y el medio ambiente en general.

Decantado lo anterior es claro que el tratamiento jurisprudencial que se ha dado a la industria extractiva es preocupante, máxime cuando hemos visto que la solución no es prohibir sino concertar. Acertado es decir que la nueva tesis jurisprudencial de la Corte Constitucional es uno de los fenómenos que ha generado más inseguridad jurídica en la actualidad; ha menguado la confianza inversionista, y por tanto, deja en una zona gris tanto la voluntad de invertir en la industria extractiva del país ${ }^{31}$, como el destino de la industria existente.

30. Pero no debe entenderse únicamente la inseguridad jurídica como un fenómeno producto de la coalición de éstos principios. Además de ello, también juega un papel fundamental el hecho de que en Colombia existe una normatividad dispersa y abundante, lo que comúnmente se conoce como hiperinflación legislativa. Para dar más claridad debemos señalar un fenómeno muy interesante que ocurrió con la Ley 1382 de 2010, la cual fue declarada inexequible con efectos diferidos por 2 años, por la Corte Constitucional mediante Sentencia C-366 de 2011; al no realizarse las correcciones que solicitaba el fallo (realizar la consulta previa), salió del ordenamiento jurídico dicha ley. Prima facie dicho acontecimiento no representa problema alguno, más no es así, un gran problema se origina pues el contenido de dicha norma, luego se empezó a incorporar en forma paulatina dentro de los Planes Nacionales de Desarrollo, un ejemplo es la Ley 1753 de 2015. Así, la normatividad para el sector minero se encuentra dispersa. Finalmente, a modo de crítica, tenemos también el Decreto Único Reglamentario 1073 de 2015, que como todos los Decretos Únicos Reglamentarios son complejos de leer y en muchas ocasiones generan confusión. Recuérdese que la normatividad tendría que ser más concisa y clara.

31. Afectando en forma latente el desarrollo industrial, o al menos, la locomotora extractiva. Con todas las contingencias que ello representa v.g. Las regalías, la generación de empleo, el suministro de materias primas para obras públicas etc.
Así pues, los principios de Coordinación, Concurrencia y Subsidiariedad que trae la Constitución Política de Colombia 199132 tendrían que aplicarse bajo una óptica del acuerdo contractual. Esta solución se debe aplicar tanto para la relación Estado- Estado, como Estado- particulares; no de otra forma es posible reconciliar las diferencias e intereses existentes. Dicho acuerdo contractual materializa el consenso y la voluntad de los agentes intervinientes ${ }^{33}$, y además logra la conciliación de los diferentes intereses que se encuentran en juego.

Dicho acuerdo contractual tendrá que llevarse a cabo, mediante una audiencia pública, previa al otorgamiento del título minero. Lo que debe realizarse es un conceso, un verdadero acto contractual; cuyo contenido sea de obligatorio cumplimiento para quienes lo suscriben, so pena de realizar pagos a título de sanción e indemnización por los perjuicios que se ocasionen a la parte cumplida.

La aplicación de dicha figura consagra en su máxima expresión los principios anteriormente mencionados, y constituye una herramienta de protección a los intereses tanto de la población civil, como del Estado y de la industria. Por ello, en el corto plazo, de implementarse ésta herramienta, se logrará reforzar la seguridad jurídica en el país ${ }^{34}$, mediante acuerdos claros, obligatorios, multilaterales y sinalagmáticos; que propendan por la consecución real del interés general.

No obstante lo anterior, es menester resaltar que dicho acuerdo contractual no exime de sus responsabilidades y papel protagónico ni al Consejo Asesor de Política Minera (CAPM), ni a la Unidad de Planeación Minero Energética (UPME), pues del correcto ejercicio de sus competencias también depende la seguridad jurídica del sector.

32. Constitución Política de Colombia de 1.991. Artículo 288.

33. Entiéndase éstos como: Nación, Entidades Territoriales y Colectividades Sociales.

34. Recuérdese además que por los daños o perjuicios producidos por una indebida gestión de la industria también se originan litigios internacionales. Tales son los contenidos en acuerdos de inversión que en muchos de los casos están respaldados por tratados de libre comercio. Un ejemplo claro es el "caso Marmato". De no cumplirse con las sanciones pecuniarias que llegaren a imponerse al país, se podría generar una crisis de cooperación comercial entre los países involucrados; de ahí que al tomarse una determinación que afecte a la industria, para este caso la extractiva, debe observarse con mucho juicio las posibles externalidades que se pudieren producir para el país. En últimas, dichas sanciones serán pagadas por todo el pueblo colombiano. 
La doctrina hace una fuerte crítica respecto del eficiente cumplimiento de las funciones a cargo del CAPM, y lo hace en este sentido:

El Consejo Asesor de Política y Normatividad Minera está adscrito al Despacho del Ministro de Minas y Energía, y tiene las siguientes funciones específicas: recomendar la adopción de medidas, la política y los mecanismos de coordinación; rendir conceptos de los proyectos que le competen; y proponer lineamientos, ajustes y prioridades de acción (Guiza, 2016: 15) (Subrayado fuera del texto)

El autor concluye que "el Consejo se enfoca en emitir recomendaciones y sugerencias sobre las medidas que se deberían aplicar por parte del sector minero, más que en establecer propuestas concretas sobre los temas en específico en los que debería hacerlo (Guiza, 2016:. 15.). (Subrayado fuera del texto),

Así, vemos que la aplicación del principio de coordinación no es exclusivamente un reto del Poder Judicial, por el contrario, dentro del ejercicio de sus competencias, debe el CAPM realizar propuestas tendientes a crear mecanismos de coordinación. El único problema, es que aparentemente no lo ha hecho. Para lo anterior tendrían que verse las Actas producto de sus reuniones, es decir, el Actas No. 17 de marzo del 2013 y el Acta No. 18 de mayo de 2014; en ellas se evidencia que dichas reuniones únicamente se realizaron una vez por año, y que además, tuvieron una duración de 2 horas y media, tiempo por demás insuficiente para proponer soluciones adecuadas para viabilizar mecanismos de coordinación. En esta línea, de conformidad con el Decreto 255 de $2004^{35}$ le asiste la competencia a la Unidad de Planeación Minero Energética (UPME). Se reestructura esta entidad y la planeación estatal para el desarrollo minero queda a su cargo. Por lo tanto, su función se concreta en planear en forma integral, indicativa y permanente el desarrollo y aprovechamiento de los recursos mineros del país, como se señala en el artículo 5 del decreto en mención, así como en el artículo $5^{\circ}$ del Decreto 4130 de 2011, por medio del cual se reasignaron funciones del sector mineroenergético (Guiza et al. 2016).

35. "Por el cual se modifica la estructura de la Unidad de Planeación Minero Energética, UPME, y se dictan otras disposiciones".
Con base en lo anterior es acertado señalar que también en cabeza de la UPME se encuentra la planificación integral para el sector mineroenergético, y que por ello, en su agenda para el año 2018 debe incorporarse además, la creación de políticas tendientes a materializar en forma efectiva la coordinación entre los órganos interinstitucionales y además, la de concertación entre el sector extractivo y las comunidades dada la relevancia que dicho acontecimiento representa en nuestro actual momento.

Luego de lo anterior, debe realizarse una práctica sana, no solamente frente a la publicidad de los proyectos mineros que se vayan a realizar en determinado territorio, sino además, frente a los mecanismos de participación de los que pueden hacer uso. La participación de todos los actores interesados es fundamental. De manera específica, el rol que le compete a la comunidad debe velar porque el proyecto se realice dentro del marco del cumplimiento de las normas legales y que este genere los menores impactos negativos posibles. Participación proactiva que apoyará el desarrollo de proyectos mineros de interés local, regional o nacional. Por lo anterior, es fundamental que el Gobierno Nacional, regional y local preste toda su colaboración para que haya claridad, entre todos los actores, de los alcances de la participación comunitaria y que facilite los mecanismos que permitan una interlocución fluida entre los inversionistas o dueños del proyecto y la comunidad. (Ministerio de Minas y Energías, 2006, citado por Guiza, et al. 2016: 128).

Finalmente, la evolución de la jurisprudencia constitucional, en buena hora, nos ha llevado a un panorama absolutamente nuevo. En comunicado No. 40 del expediente con radicado No. T-629895 en la Sentencia SU-095 del 11 de octubre de $2018^{36}$, la Corte Constitucional modificó la posición existente frente al poder que tienen las consultas populares para prohibir el desarrollo de la actividad extractiva en los municipios.

En dicho comunicado se informó la prohibición de realizar cualquier tipo de veto a la industria extractiva ya que dicho acto choca en

36. Colombia. Corte Constitucional. Comunicado No. 40 Expediente con radicado No. T-629895 en la Sentencia SU095 del 11 de octubre de 2018. Consultado en: http://www. corteconstitucional.gov.co/comunicados/No.\%2040\%20 comunicado\%2011\%20de\%20octubre\%20de\%202018.pdf (29/10/2018; 23:38 Hrs.) 
forma directa con las competencias propias del orden central. Y por lo mismo exhorta al Congreso de Colombia a establecer uno o varios métodos que logren de forma efectiva materializar los postulados de coordinación y concurrencia entre las competencias de los órganos del orden central y descentralizado. Dichos mecanismos deben incorporar además las siguientes reglas: (...) i) Participación ciudadana y pluralidad; ii) Coordinación y concurrencia nación territorio; iii) Inexistencia de un poder de veto de las entidades territoriales para la exploración y explotación del subsuelo y de recursos naturales no renovables; iv) Diferencialidad / Gradualidad; v) Enfoque Territorial.; vi) Legitimidad y Representatividad; vii) Información previa, permanente, transparente, clara y suficiente; viii) Desarrollo sostenible; ix) Diálogo, comunicación y confianza; $\mathrm{x}$ ) Respeto, protección y garantía de los derechos humanos; xi) Buena Fe; xii) Coordinación y fortalecimiento de la capacidad institucional nacional y territorial y, xiii) Sostenibilidad fiscal.

Llama la atención dentro de las reglas, la incorporación del numeral iii), pues con el ya da a entender que bajo ningún aspecto le será permitido a los municipios o departamentos vetar el desarrollo de la actividad extractiva, así se utilicen mecanismos de participación ciudadana, pues dicha actuación se habrá de entender como inconstitucional.

Es muy acertada dicha premisa ya que bajo ningún aspecto se debe desconocer que el producto de las regalías por concepto de la actividad extractiva, termina siendo un elemento esencial para el desarrollo de los proyectos de utilidad pública de la nación en general.

Ahora bien, con dicho pronunciamiento el panorama para la seguridad jurídica y la inversión en el sector es más claro, y propugna por un avance sostenible y armónico del ejercicio de las competencias de los distintos órdenes. Habrá que ver qué sucede con la tarea encomendada al Congreso de la República, y además, que impactos tendrá esta decisión en los distintos órdenes territoriales en el país. El gran reto apenas comienza. 


\section{BIBLIOGRAFÍA}

- Constitución Política de Colombia. (1991). Gaceta Constitucional No. 116, Bogotá, Colombia, 20 de julio de 1991.

- Corte Constitucional. (2014). Sentencia C-123 del 5 de marzo de 2014. M.P. Alberto Rojas Ríos.

- Corte Constitucional. (2015). Sentencia C-493 del 5 de agosto 2015. M.P. María Victoria Calle Correa.

- Corte Constitucional. (2016). Sentencia T-445 del 19 de agosto 2016. M.P. Jorge Iván Palacio.

- Corte Constitucional. (2018). Comunicado No. 40. Expediente con radicado No. T-629895 en la Sentencia SU-095 del 11 de octubre de 2018.

- Chevallier, J. (2011). El estado posmoderno. Bogotá: Universidad Externado de Colombia.

- Ferrajoli, L. (2013). Democracia y garantismo. (2nd ed.). Madrid: Editorial Trotta.

- Guiza, L. et al. (2016). Actualidad y desafíos del derecho minero colombiano. Bogotá: Editorial Universidad del Rosario.

- Ley 99 de 1.993. Diario Oficial No. 41.146, Bogotá, Colombia, 22 de diciembre de 1993.

- Ley 685 de 2001. Diario Oficial No. 44.545, Bogotá, Colombia, 15 de agosto de 2001.

- Ley 1382 de 2010. Diario Oficial No. 47.618, Bogotá, Colombia, 9 de febrero de 2010.

- Ley 1753 de 2015. Diario Oficial No. 49.538, Bogotá, Colombia, 9 de junio de 2015.

- Pérez, A. (1991). Las generaciones de derechos humanos. Revista del Centro de Estudios Constitucionales, (10), 203-217.

- Pérez, A. (1999). Derechos humanos Estado de Derecho y Constitución. (10ma ed.). Madrid: Editorial Tecnos.

- SEMANA. (2018). Colombia da vía libre a la protección de sus páramos, ¿cómo llevarla del papel a la realidad?. 28 de junio de 2018. Disponible en: https://www.semana. com/Item/ArticleAsync/573367?next Id $=573408$ 